\title{
Geomorphometry in Landscape Ecology: Issues of Scale, Physiography, and Application
}

\author{
Kirsten Erin Ironside ${ }^{1, *}$, David J. Mattson ${ }^{1}$, Terence Arundel ${ }^{1}$, Tad Theimer ${ }^{2}$, Brandon Holton ${ }^{3}$, \\ Michael Peters ${ }^{4}$, Thomas C. Edwards, Jr. ${ }^{5}$, Jered Hansen ${ }^{1}$ \\ ${ }^{1}$ U.S. Geological Survey, Southwest Biological Science Center, United States \\ ${ }^{2}$ Biological Sciences Department, Northern Arizona University, United States \\ ${ }^{3}$ National Park Service, Grand Canyon National Park, Science and Resource Center, United States \\ ${ }^{4}$ Pterylae Systems, Arizona, United States \\ ${ }^{5}$ U.S. Geological Survey, Utah Cooperative Fish and Wildlife Research Unit, Department of Wildland Resources, \\ Utah State University, United States
}

Copyright $\bigcirc 2018$ by authors, all rights reserved. Authors agree that this article remains permanently open access under the terms of the Creative Commons Attribution License 4.0 International License

\begin{abstract}
Topographic measures are frequently used in a variety of landscape ecology applications, in their simplest form as elevation, slope, and aspect, but increasingly more complex measures are being employed. We explore terrain metric similarity with changes in scale, both grain and extent, and examine how selecting the best measures is sensitive to changes in application. There are three types of topographic measures: 1) those that relate to orientation for approximating solar input, 2) those that capture variability in terrain configuration, and 3) those that provide metrics about landform features. Many biodiversity hotspots and predators have been found to coincide with areas of complexity, yet most complexity measures cannot differentiate between terrain steepness and uneven and broken terrain. Currently characterizing terrain in landscape-level analyses can be challenging, especially at coarser spatial resolutions but developing methods that improve landscape-level assessments include multivariate approaches and the use of neighborhood statistics. Some measures are sensitive to the spatial grain of calculation, the physiography of the landscape, and the scale of application. We show which measures have the potential to be multi-collinear, and illustrate with a case study how the selection of the best measures can change depending on the question at hand using mountain lion (Puma concolor) occurrence data. The case study showed a combination of infrequently employed metrics, such as view-shed analysis and focal statistics, outperform more commonly employed singular metrics. The use of focal statistics as a measure of topographic complexity shows promise for improving how mountain lions use terrain features.
\end{abstract}

Keywords Habitat, Topography, Terrain, Ruggedness, Mountain Lion, Puma concolor

\section{Introduction}

Techniques for characterizing and quantifying land and benthic surfaces have been utilized by many biological and ecological fields of study, in addition to the fields of geomorphology, soil science, and remote sensing from which they are typically derived. A wide assortment of measures has been developed as a result of a cross-disciplinary approach required to capture landscape or seascape features. With the coming of the digital age, geomorphology and geography gave rise to geomorphometry, the science of topographic quantification where the primary objective is to quantify surface parameters from digital elevation models (DEMs) [1]. Currently, many software tools and parameters have been developed with advances in Geographic Information Systems (GIS). Measures first developed for geomorphological or remote sensing applications are now being applied to ecological questions, such as evaluating species' resource selection of "rugged" terrain [2]. As with many fields of study, semantics in geomorphometry [1] have been problematic for describing what a topographic measure captures. Topographic features can play a fundamental role in many biological, ecological, and evolutionary processes. Some features such as large mountain ranges or low elevation valleys may form barriers to movement and gene flow for some species. Terrain aspect determines amounts of energy input in the form of solar radiation, in turn affecting evapotranspiration rates and contributing to the evolution of plant phenology and adaption to xeric or mesic conditions. Similarly, in animals, terrain has contributed to the evolution of 
morphological features for animal locomotion, where species such as the modern day African cheetah (Acinonyx jubatus) has evolved cursorial locomotion and predation, and is able to run for long distances over flat terrain to obtain prey. Whereas a common ancestor, the American puma (Puma concolor) [4], also commonly referred to as mountain lions, is unable to run long distances, and relies on saltatorial (leaping and pouncing) or scansorial (climbing) locomotion for evasion and hunting $[5,6]$.

Because terrain has played a significant role in species' morphological adaptation and evolution, some metric of it is inevitably incorporated into evaluations of species' habitat requirements. Landscape ecologists conducting analyses related to distribution modeling, wildlife resource selection functions, habitat connectivity, or simulating movement patterns, frequently incorporate topographic features to describe how organisms or genes are distributed across environments. Many of these metrics serve as an indirect measure of how organisms respond to their environment (Figure 1). For example, aspect may serve as a proxy for evapotranspiration rates that are directly related to vegetation growth, distribution, and structure [7]. In turn, the vegetation associated with particular aspects may be selected by various animal species for food and cover. Terrain configurations that result in a large degree of heterogeneity of aspects and form have in turn been good metrics of species richness [8].

How topographic features are characterized can have pronounced influence on the results of such analyses. The use of GIS in ecology is widespread for understanding the spatial structure of environmental systems from biotic to the abiotic features that influence their occurrence, abundance, and community structure. In practice, landscape ecologists are faced with many options when incorporating topography into analyses of spatial patterns. Options include selecting a metric or metrics to employ, deciding the appropriate spatial grain to calculate them, and, for many topographic metrics, choosing an appropriate analysis window. Analysis windows can be set in various shapes (circular, rectangular, oblong, etc.) and be conceptually infinite in size. The similarity of one terrain metric to another is not always clear, nor the degree of sensitivity to changes in specification and application. When comparing one study to another employing a different metric, the influence of using a different topographic measure on results is not easily ascertained for most. Little consensus exists on which measures are the most appropriate for various applications.

Geomorphometric measures are predominately of two types, those concerned with orientation of topographic features and those concerned with landscape configuration - the most commonly derived metrics being aspect and slope (Figure 1). Efforts to improve how the orientation of topographic features relates to solar input have resulted in numerous metrics for quantifying solar radiation, from simple mathematical transformations of aspect to complex models of solar insolation that account for seasonal changes in sunlight, latitude, and shadowing [9-11]. Efforts to capture the heterogeneity of three-dimensional characteristics of land or benthic surfaces have been described as those capturing topographic complexity, and are commonly referred to as roughness or ruggedness measures. Many metrics were developed to measure the form of topographic features for geomorphology and landform classification schemes (Figure 1). Various metrics fall into this category such as those used for measuring exposure, view-sheds, topographic positioning, and curvatures of features. Often these continuous variables are classified into various landform descriptions such as valleys, toe-slopes, ridges, draws, peaks, etc. [12] and have a strong association with soil and hydrological characteristics [1]. Similar to the effect of aspect, landforms have been associated with plant growth and structure $[13,14]$ and how animals move through the landscape [15].

Issues of scale are a recurring topic in landscape ecology and are commonly described in terms of how grain and extent influence inference [16-18]. Field studies of nature tend to have correlated grain and extent, where studies over smaller extents can record more detail, and studies over larger extents tend to sacrifice grain for purely logistical reasons [19]. Advances in remote sensing and computing though are making fine grain assessments over larger areas more commonplace. As a result, more attention is being given to the modifiable areal unit problem (MAUP) to identify relationships between metrics of landscape heterogeneity and gradients, and scale. Robust spatial grain scaling relationships have been found for both continuous surface metrics [20] and metrics of spatial heterogeneity [21]. How rescaling may result in systematic biases and create spatial dependencies in landscape pattern-process relationships is a current research challenge for landscape ecologists [21]. The grain in geomorphometric applications is equivalent to the cell size of the DEM, and the extent being the spatial area of study, equivalent to the number and location of DEM cells. We explore the effects of grain and extent by changing DEM cell size and spatial extents that result in changes in the physical features included in the extent. 


\section{Digital Elevation Model (DEM)}

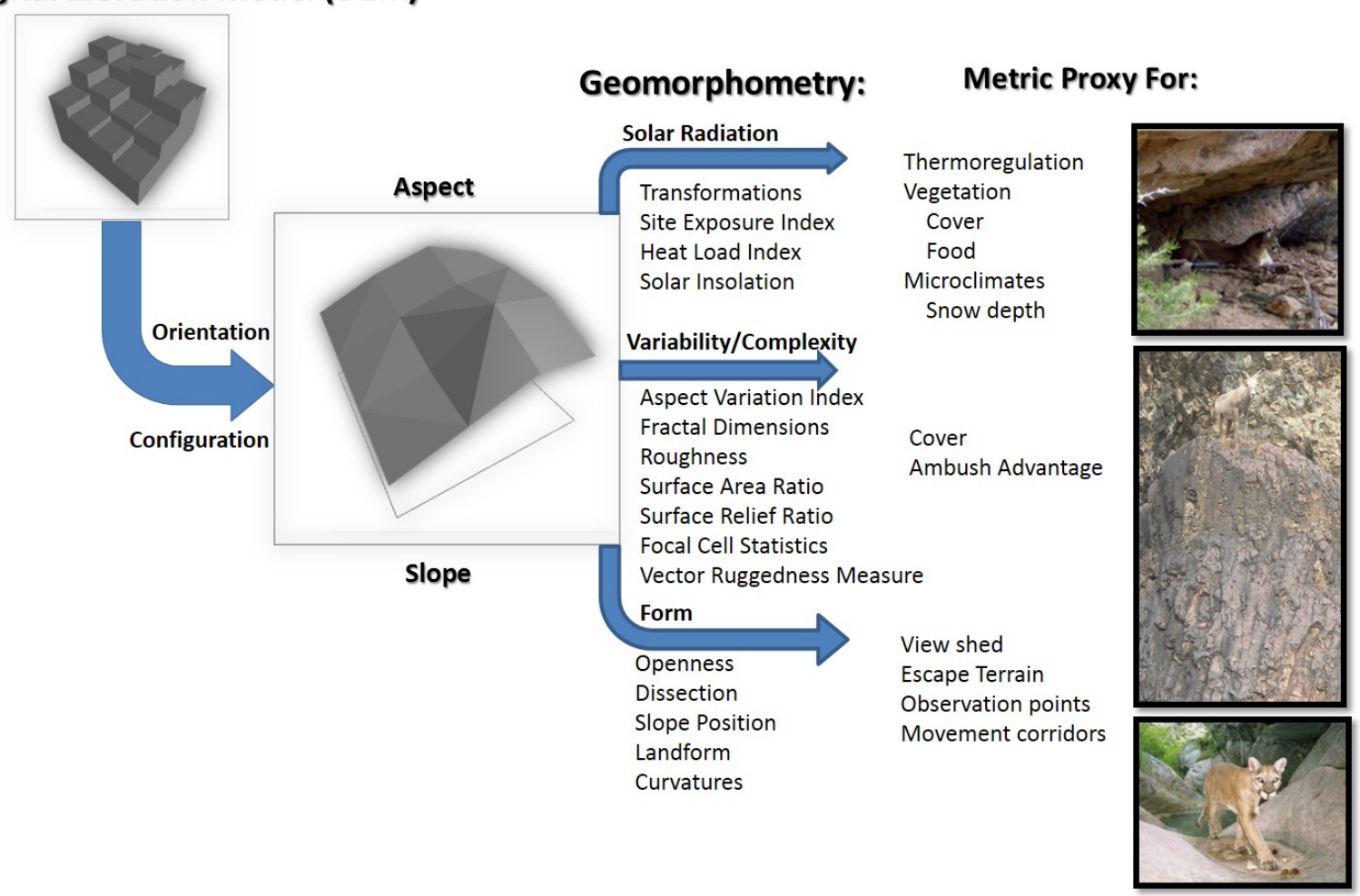

Figure 1. Digital Elevation Models (DEMS) are used for a variety of landscape metrics, sometimes just as raw 3-dimensional coordinates, and often as slope and aspect. Several other metrics have been developed for quantifying the effects of solar radiation, including several transformations of aspect, indices of relative solar inputs, and complex models of solar insolation. Measures of orientation have strong influences on vegetation, evapotranspiration, and snow accumulation. DEMs have also been used to quantify topographic complexity and landforms. These metrics can serve as proxies, such as slope, which is often used to describe escape terrain for bighorn sheep, and mountain lions have been described as selecting for rugged terrain. Photographs courtesy of the U.S. Geological Survey.

Geomorphometry adds another level of complexity related to scale that remains largely unexplored. For many metrics an analysis window must be set, resulting in an extent within an extent, which can be specified for various shapes, sizes, and directionality. We did not explore the effects of variation in the size and shape of the analysis window and this is an area in need of further research. For most reviewed metrics that we calculated to explore the effects of scale (grain and study area extent), the default rectangular $3 \times 3$ cell analysis window was used. Issues related to how parametrization of analysis windows are specified have been explored by Wood [22] and methods are available in Landserf software for exploring sensitivities of the analysis window to scale (www.landserf.org). Future planned versions of the FRAGSTATS software program will also incorporate neighborhood statistics of continuous variables, in addition to the landscape-level spatial patterns of categorical mapping already implemented

(http://www.umass.edu/landeco/research/fragstats/fragstat s.html).

Most evaluations of the relationship between biotic factors and topography are equivalent to quantifying the association with or distance from particular topographic features, without consideration of the surrounding conditions. We explore the use of focal cell statistics (e.g. neighborhoods) to describe terrain variability of a given area, capturing the degree of undulation, and explore the idea that animals may be selecting for areas of particular topographic configuration, rather than particular topographic features such as a ridgeline. This is similar to exploring how future planned versions of FRAGSTATS may contribute to improving landscape level analyses.

Physical geography in the earth sciences, related to large scale geomorphological studies, have given rise to several metrics for describing the physical forms of the earth's surface. Often used to classify landforms such as volcanoes, plateaus, canyons, etc. these metrics have also been applied to biological studies related to how organisms are distributed. Since the advent of digital elevation models, researchers recognized that characterizing topographic features across the landscape was not a trivial exercise; this resulted in a new area of research, geomorphometry. This subdiscipline of geomorphology and physiography has given rise to numerous metrics on which we measure topography. Many of these measures have been adopted for use in wildlife assessments of habitat and other ecological topics, and found to be influential determinants 
of community dynamics and richness, shaping species activity patterns, and contributing to evolutionary histories in both marine and terrestrial environments [8, 23-28]. Not only does topography represent a relatively static physical feature of the landscape but it also shapes many indirect and dynamic features of the landscape. For example, orientation has been a good indicator of evapotranspiration rates, snow accumulation and melt-off rates, affecting the timing of green-up, and therefore shaping how many wildlife species use the environment [23]. A previous review found many metrics are very similar to one another, yet calculated differently [23]. We expand on this previous research to explore how changes in grain and study area extent that result in different physical forms being represented, influence similarity between metrics. The physiography of areas covered includes a large canyon system, a volcanic field, a series of mountainous peaks, and a mesa.

\section{Materials and Methods}

In addition to slope, we evaluate seven measures related to aspect/orientation calculations, eight measures related to capturing topographic complexity and variability, and nine measures that were developed for landform classification. Though many of these measures have traditionally been binned into classification schemes, notably aspect, we prefer a continuous representation of parameters. Cushman et al. [29] argue for landscape ecologists to accurately identify pattern and process across landscapes, so there is a need to adopt a gradient approach and move away from the more traditional patch and mosaic approach to viewing the landscape. We support this view and therefore compare all measures as continuous parameters. Differences in classification schemes add one more level of complexity when attempting to compare studies using different metrics.

We selected metrics that have been implemented in a wide array of landscape and seascape level studies and those geomorphometrics that are readily available in software packages. Most habitat assessments just simply use elevation or depth in marine environments, which can lack theoretical or practical contexts in how organisms are relating to topography. Elevation in this raw form is no more than a referenced position in three-dimensional space, similar to latitude and longitude and can be a misleading topographic measure [23]. For studies that have sought to measure topographic features, there is often reliance on a particular metric by a researcher. The fact that no metric has gained wide acceptance among researchers (other than the uninformative use of elevation), suggests terrain may need several combinations of metrics to adequately describe the landscape $[23,28]$. The few explorations into multivariate characterization of topography in investigations of wildlife resource use, suggest this approach is optimal [2, 23, 30, 31].

In support of this multivariate approach, we provide similarity metrics between measures, by providing correlation coefficients which are commonly used to screen variables for potential problems with multicollinearity [32], or as criteria to combine into principle components. We also cover a wide range of physiographic features and change in scale to demonstrate their effects on metrics. Lastly, we explore ways to implement the use of geomorphometrics in resource selection of a large mobile predator, often associated with areas of topographic complexity in the western North American portion of its range.

We used two GIS software packages, ArcGIS v10.2 [33] and LandSerf [22]. Additionally, we used Python 2.7 scripts in ArcGIS or as stand-alone processes. ArcGIS calculations included the use of the Spatial Analyst extension and custom GIS python scripts developed by Evans et al. [34] and the authors here [35]. Measures were calculated from $1 \times 1$-degree DEM tiles obtained from the 1 arc second USGS seamless National Elevation Dataset (NED) [29]. Processing steps included mosaicking tiles for the study area extent, projecting from the native geographic coordinate system to Universal Transvers Mercator (UTM) North American Datum of 1983 (NAD83) zone 12 north, and running focal statistics using a 2-cell circular radius bilinear resampling window to remove artifacts or pits in the DEM [12]. The cell size was set to 30-m resolution. We created a second DEM dataset from this $30-\mathrm{m}$ dataset, by resampling using bilinear resampling to a $1-\mathrm{km}$ resolution.

\subsection{Orientation}

Measures numbered one through six were calculated using the Geomorphometric and Gradient Metrics Toolbox [34] in ArcGIS v10.2 [33].

\subsubsection{Linear Aspect}

It transforms circular aspect, in radians, to a linear variable using focal statistics for a given window. Focal statistics for a given window (defaults to $3 \times 3$ ) is run for:

$$
\begin{aligned}
& \text { Aspect }_{s}=\sin \left(\frac{180}{\pi}\left(2 \pi+\frac{\pi}{2}\right)-\text { Aspect }_{\text {radians }}\right) / \frac{180}{\pi} \\
& \text { Aspect }_{c}=\cos \left(\frac{180}{\pi}\left(2 \pi+\frac{\pi}{2}\right)-\text { Aspect }_{\text {radians }}\right) / \frac{180}{\pi} \\
& \text { Aspect }_{\text {linear }}=\left(\frac{180}{\pi}\left(2 \pi+\frac{\pi}{2}\right)-\arctan \left(\frac{\text { Aspect }_{s}}{\text { Aspect }_{c}}\right) \frac{180}{\pi}\right) \bmod 2 \pi\left(\frac{180}{\pi}\right)
\end{aligned}
$$

\subsubsection{COS and SIN Transformations of Aspect}

These metrics assume the northeast azimuth of $45^{\circ}$ is a maximum and the southwest quadrant can be an empirically derived minimum [7]. For slopes from $0 \%-$ $100 \%$, the functions are linearized and bounded from -1 to 1 and slopes greater than $100 \%$ are treated as no data. 


\subsubsection{Topographic Radiation Aspect Index (Transformed Aspect - TRASP)}

Circular aspect is transformed to a value of zero for north- northeast azimuths, and a value of one for southwesterly azimuths, resulting in a continuous variable between $0-1$ [36];

$$
\text { TRASP }=\frac{1-\cos \left(\left(\frac{\pi}{180}\right)\left(\text { Aspect }^{\circ}-30\right)\right)}{2}
$$

\subsubsection{Site Exposure Index (SEI)}

Circular aspect is rescaled to a north/south axis and is weighted by the steepness of the slope on a scale from -100 to 100 [37];

$$
\mathrm{SEI}=\theta \cos \left(\pi \frac{\alpha-180}{180}\right)
$$

\subsubsection{Heat Load Index (HLI)}

Southwest facing slopes are found to be warmer than a southeast facing slope, even though the amount of solar radiation they receive is equivalent. HLI accounts for this by "folding" the aspect so that the highest values are southwest and the lowest values are northeast. In addition, this method includes steepness of slope. This index ranges from 0 (coolest) to 1 (hottest) [38];

$$
\begin{gathered}
f_{s}=|\pi-| \text { Slope }_{\text {radians }}-\frac{5 \pi}{4}|| \\
\text { HLI } 0.039\left[0.808^{*} \cos (\mathrm{l}){ }^{*} \cos (\theta)\right]- \\
-[0.196 * \sin (\theta)]-\left[0.482^{*} \cos \left(\mathrm{f}_{\mathrm{s}}{ }^{*} \sin \left(\mathrm{f}_{\mathrm{s}}\right)\right)\right.
\end{gathered}
$$

\subsubsection{Solar Insolation}

We used ArcGIS v10.2 [33] Spatial Analyst extension to calculate an annual global solar insolation raster. The solar radiation analysis tools calculate insolation across a landscape based on methods from the hemispherical view-shed algorithm initially developed by Rich et al. [10, 11] and further developed by Fu \& Rich [39, 40].

\subsection{Complexity}

\subsubsection{Aspect Variation Index (AVI)}

We used ArcGIS v10.2 [33] Spatial Analyst extension to calculate a measure of topographic complexity used in Neilson et al. [41] that measures variability in aspects. Aspect variation was measured in a rectangular $3 \times 3$ cell analysis window using Spatial Analyst's Neighborhood focal statistics variation (count of different aspect classes in the surrounding cells) for an aspect raster reclassified into flat, N, NE, E, SE, S, SW, W, and NW (the default classes in Spatial Analysts aspect tool). Average slope was measured in a rectangular $3 \times 3$ cell analysis window using Spatial Analyst Neighborhood focal statistic's mean function.

$$
\begin{gathered}
\mathrm{AVI}=(\text { aspect variation } \mathrm{x} \text { average slope }) \\
/(\text { aspect variation }+ \text { average slope })
\end{gathered}
$$

\subsubsection{Fractal Dimensions (D)}

We used Landserf v2.3 [22] to calculate fractal dimensions using the minimum allowable analysis window of 9x9 cells. Fractal dimensions are indices of geometric irregularity of a surface with flat values given a value of 2 and infinitely "crumpled" surfaces having values of 3 . Surfaces with values of 2 are often bodies of water or other perfectly level features on the landscape. $\mathrm{D}$ is an indicator of relief complexity derived from a fractal Brownian motion model and variograms [42]. The expected value of the squared elevation difference between two DEM cells, $p$ and $\mathrm{q}$, is;

$$
\sum\left(\mathrm{Z}_{\mathrm{p}}-\mathrm{Z}_{\mathrm{q}}\right)^{2}=\mathrm{k}\left(\mathrm{d}_{\mathrm{pq}}\right)^{2 \mathrm{H}}
$$

where the variance is calculated using the mean of the squared height and $\mathrm{H}$ equals 3-D

$$
\mathrm{D}=3-\left(\frac{\mathrm{b}}{2}\right)
$$

where $b$ is the slope of a log-log plot of variance against distance

\subsubsection{Surface Area Ratio (SAR)}

We calculated SAR using the Geomorphometric and Gradient Metrics Toolbox [34] in ArcGIS v10.2 [33], a metric developed to capture rugosity, by calculating the ratio of surface area to planar area $[43,44]$. Surface area is calculated using triangulated irregular networks (TINs) calculated from DEMs and planar area calculated from the analysis window of the DEM.

\subsubsection{Roughness}

We calculated roughness using the Geomorphometric and Gradient Metrics Toolbox [34] in ArcGIS v10.2 [33]. This measure is also commonly referred to as the terrain ruggedness index (TRI) Riley [45-47], which is a focal cell statistic of the variance in elevation values for a given analysis window. Here it is calculated as the focal square-root of the summed differences in elevations of neighboring cells for a $3 \times 3$ analysis window.

\subsubsection{Standard Deviation of Elevation}

We included a focal cell statistic as a potential measure of topographic complexity by using ArcGIS v10.2 [33] and the Spatial Analyst extension. The standard deviation, the variance about the mean, of a rectangular analysis window of $3 \times 3$ cells was calculated from the DEMs.

\subsubsection{Standard Deviation of Total Curvature}

We developed a measure of topographic complexity, by using focal cell statistics in ArcGIS v10.2 [33] Spatial Analyst extension to calculate the standard deviation of total curvature using the default $3 \times 3$ cell analysis window (see below for methods on the calculation of total curvature). 


\subsubsection{Vector Ruggedness Measure (VRM)}

We used a VRM Python script written for ArcGIS v10.2 [33] to calculate this measure of ruggedness by Sappington et al. [2]. VRM is a standardized measure of the three-dimensional dispersion of vectors orthogonal to slope gradients and aspects of a surface derived from DEMs.

$$
V R M=1-\frac{\sqrt{\left(\sum x\right)^{2}+\left(\sum y\right)^{2}+\left(\sum z\right)^{2}}}{n}
$$

where $\mathrm{n}$ is the number of cells in the neighborhood and the vectors $\mathrm{x} . \mathrm{y}$, and $\mathrm{z}$ are equal to

$$
\begin{gathered}
z=\cos (s) ; x=x y \times \sin (\alpha) ; x y=\sin (\alpha) ; \\
\text { and } y=x y \times \cos (\alpha)
\end{gathered}
$$

where $\mathrm{s}$ is the orthogonal slope and $\alpha$ is the angle between the orthogonal slope and the vectors

\subsubsection{Surface Relief Ratio (SRR)}

We calculated SRR using the Geomorphometric and Gradient Metrics Toolbox [34] in ArcGIS v10.2 [33]. SSR is a measure of rugosity or ruggedness of a continuous raster surface developed by Pike \& Wilson [48]. We used the default rectangular $3 \times 3$ cell analysis window.

$$
S R R=\frac{\overline{\mathrm{z}}(\mathrm{s})-\mathrm{z}(\mathrm{s})_{\min }}{\mathrm{z}(\mathrm{s})_{\max }-\mathrm{z}(\mathrm{s})_{\min }}
$$

where $\mathrm{z}$ is the elevation and $\mathrm{s}$ is the analysis window size.

\subsection{Form}

\subsubsection{Positive Openness}

We calculated positive openness using the methods of Yokoyama et al. [49] in Python 2.7 [35]. Positive openness is an index incorporating the terrain line-of-sight, or view-shed concept for measuring terrain exposure to the sky and is calculated from a DEM by averaging the zenith angles that are within an arbitrary radius from a central cell for each cardinal and ordinal direction. Openness has high values for convex landforms and low values for concave landforms. Positive openness was calculated using a 480-meter search radius.

\subsubsection{Dissection}

We calculated dissection using the Geomorphometric and Gradient Metrics Toolbox [34] in ArcGIS v10.2 [33]. Dissection is a measure meant to describe a location's configuration relative to surrounding locations. Evans et al.'s [34] toolbox implements Martonne's modified dissection [50] which is calculated as:

$$
\text { dissection }=\frac{\mathrm{z}_{i}-\mathrm{z}(\mathrm{s}) \min }{\mathrm{z}(\mathrm{s}) \max -\mathrm{z}(\mathrm{s}) \min }
$$

where $\mathrm{z}$ is the elevation, $\mathrm{i}$ is the focal cell, and $\mathrm{s}$ the analysis window size.

\subsubsection{Slope Position}

We calculated slope position using the Geomorphometric and Gradient Metrics Toolbox [34] in ArcGIS v10.2 [33]. Slope position, also known as Topographic Position Index (TPI) is calculated using the methods in De Reu et al. [51] and Guisan et al. [52]. This metric calculates scalable slope position by subtracting the average neighbor values from the focal value. Positive values indicate that the central point is located higher than its average surroundings, while negative values indicate a position lower than the average.

\subsubsection{Landform}

We calculated landform curvature using the Geomorphometric and Gradient Metrics Toolbox [34] in ArcGIS v10.2 [33]. Measuring curvatures has been a popular geomorphometric for landform classifications as they capture convexity and concavity. Evans et al. [34] use Bolstad's variant [51] of surface curvature, an index based on features that confine the view from the focal cell of a $3 \times 3$ cell window of analysis. A correction measure for edges is used by dividing by the radius to the outermost cell $[52,53]$.

\subsubsection{Curvatures}

Many variants of curvature calculations exist. Here we include cross-sectional and longitudinal curvature calculations available in Landserf v 2.3 [22] and the total, profile, and plan curvature calculations $[13,14]$ available in ArcGIS v10.2 [33] Spatial Analyst extension. Similar to the landform calculation above, these are meant to measure convexity and concavities in various directions using the second derivative.

\subsection{Case Study}

\subsubsection{Effects of Changes in Grain and Physiography on} Correlations between Metrics

Our case study explores wildlife resource selection applications where topography plays a strong role in habitat selection and detectability. Many wildlife population surveys can be influenced by terrain, either altering visibility or by making access logistically difficult [54]. Marking animals with GPS or radio tracking devices is a common study method to monitor animal movements over landscapes, but is also known to be biased by terrain that blocks satellite and radio signals $[55,56]$. We explore how a landscape level of analysis is conducted can affect which measures are selected by alternating sampling design and correcting for sampling bias.

Our study area, located in northern Arizona, United States of America, is known worldwide for its topographic complexity, exemplified by the Grand Canyon. We also included areas to the south of the Grand Canyon, encompassing the San Francisco volcanic fields and an area known as Anderson Mesa, located southeast of Walnut Canyon National Monument. This study area 
extent encompasses several different landforms and is also the location of a long-term study of mountain lions, Puma concolor, that were tagged with GPS telemetry collars (Figure 2) [57]. We evaluated how similar metrics are to one another using Pearson product moment correlation, which evaluates the linear relationship between two continuous variables using Minitab 17 statistical software. We compare the entire study area at $1-\mathrm{km}$ resolution and $30-\mathrm{m}$ resolution using a random sample of 72,804 cells within the study area boundaries (Figure 2A). We then subdivide the study area based on selected home-ranges of mountain lions, equivalent to the 90th isopleth of utilization distributions calculated using the Local Convex Hull ( $\mathrm{LoCoH})$ method [58], that represent distinct physiographies within the study area (Figure 2). We represent the following landforms: canyons (Figure 2B), gentle rolling hills (Figure 2C), an inactive volcanic field of cinder cones (Figure 2D), mountainous peaks (Figure 2E), and mesa/plateau (Figure 2F). These areas are calculated and compared at a 30-m resolution. Standard deviation and coefficients of variation of the correlation coefficients were calculated across the five sub-regions to measure sensitivity of metric similarity due to changes in extent and physiography.

In general, most measures were more related to one another when calculated at a coarser scale $(1-\mathrm{km})$, but not all metrics responded similarly (Figure 3). As a group, measures of orientation were largely not affected in their relationship to one another by the change in grain. The correlations between slope and measures of topographic complexity were stronger at the coarser resolution than the finer resolution. The Aspect Variation Index was the most sensitive to change in scale in its relationship with slope, with it being more correlated at the $1-\mathrm{km}$ resolution. Similarly, it was more similar to the other complexity measures at the coarser scale. Measures of topographic form had the most congruent response as a group, where most measures were slightly more correlated at the $1-\mathrm{km}$ resolution. Positive openness was found to be the most sensitive to scale change for measures of form. It also is a rather unique measure with relationships to slope, solar insolation, complexity metrics, and form metrics. At a $1-\mathrm{km}$ resolution, it was less inversely related to slope and complexity measures, than at $30-\mathrm{m}$. At $1-\mathrm{km}$ resolution, openness is more positively related to measures of form than at 30-m (Figure 3).

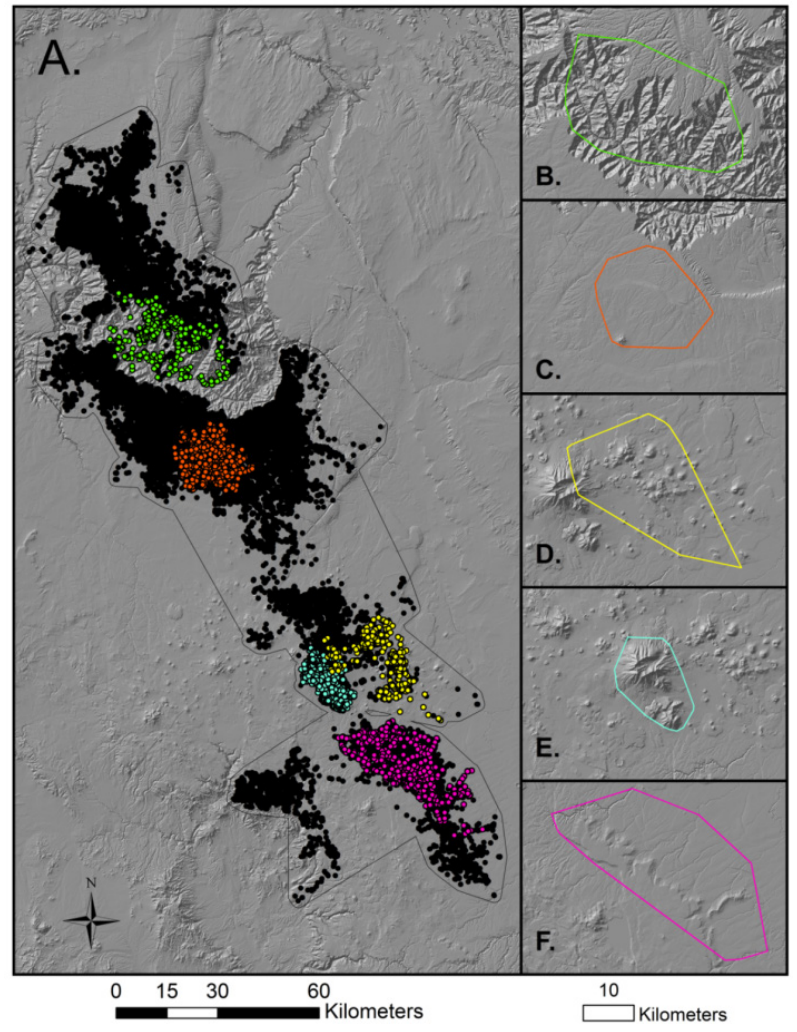

Figure 2. Study area hillshade (A.) shown with all GPS locations collected from mountain lions in northern Arizona. The black line shows the boundary where random background points were drawn. Color points are from selected mountains whose home ranges represent different physiographic regions (B.-F.) 


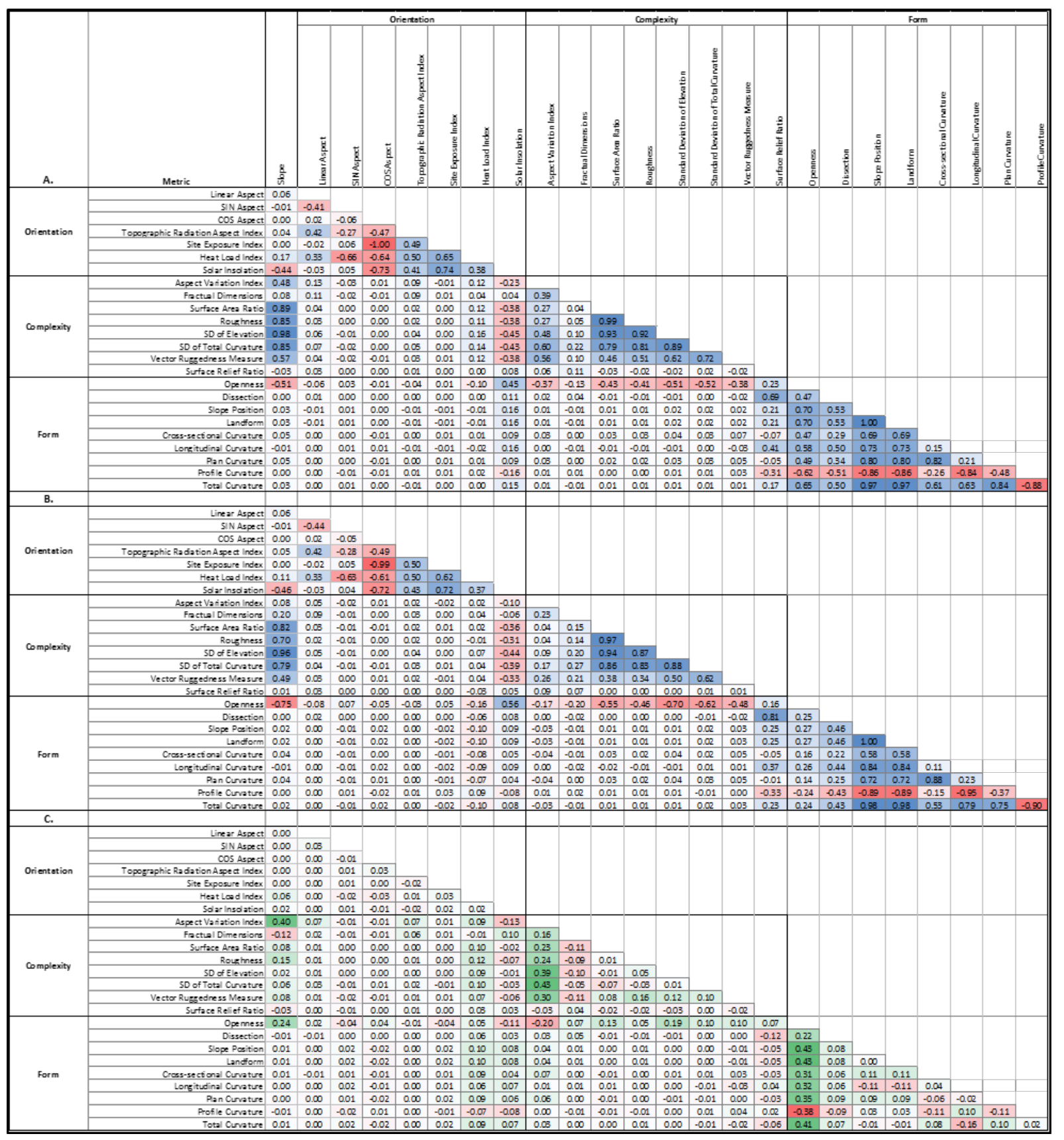

Figure 3. Heat map Pearson correlation coefficient matrix for metrics calculated at $1 \mathrm{~km}$ resolution (A.) and 30-m resolution (B.) with shades of blue showing strong positive correlations and shades of red strong negative correlations. The difference in correlation coefficients between scales is shown in part $\mathbf{C}$.

Changes in physiography also influence the similarity between measures within and between groups. The mean correlation across the five different sub-regions is shown in Figure 4A. Using standard deviation of the correlation coefficients across the five physiographic regions as a measure of sensitivity to change, we found Vector Ruggedness Measure to be the most sensitive (Figure 4B), though most metrics varied to some degree with changes in physiography and extent. Using coefficients of variation (Figure 4C) showed variation between groups for cross correlations of orientation and complexity, and complexity and form. The most variable were sine of aspect, openness, and standard deviation of total curvature. Metrics within groups of orientation and form were relatively stable with the changes in extent. Most metrics that showed sensitivity to changes in physiography had low correlation coefficients, and those with high Pearson correlation coefficients were relativity stable in their similarity with one another across extents.

\subsubsection{Effects of Changes in Grain on Habitat Selection}

Mountain lion capture, GPS collar tagging, and release 
has been conducted (Northern Arizona University IACUC Protocol \# 02-082-R4) in northern Arizona from 2003-2014 by the U.S. Geological Survey and the National Park Service, resulting in the GPS tracking and monitoring of 58 study animals (Figure 2). We evaluate two scales of application, one at a population level and the other at the level of an individual. The population-level analysis includes all observations from all mountain lions monitored in northern Arizona compared to an equal sample of random background conditions across the study area. At the level of an individual we accounted for the movement capacity of the individual using step-lengths. We explore the effects of bias correction on metric selection by weighting observations by the inverse probability of obtaining a GPS fix $[35,56]$. Because the probability of obtaining a fix is strongly related to topographic exposure (positive openness) in the model we employ [49], this has the potential to influence which measures are selected in a model selection framework.

For the population-level analysis we compared topographic complexity and form metrics at a weighted $1-\mathrm{km}$ resolution, a weighted $30-\mathrm{m}$ resolution, and an unweighted 30-m resolution. We used changes in deviance to rank measures best describing where mountain lions occur versus an equally sized random background sample of the study area. This represents a coarse resolution analysis in space and time, meant to encompass broad-scale average selection for a multitude of life-stages and activities. We hypothesize that there is an interaction between topography and vegetative cover as a mountain lion moves across the landscape. It is likely they prefer some type of cover at all times, either via the darkness of night when active, or in the form of vegetative cover and/or rough terrain during the day. Therefore, all topographic metrics of terrain had interaction terms with vegetation height in logistic regression models of use versus availability [62] using the LANDFIRE Existing Vegetation Height (EVH) [63] dataset. We also hypothesized that topographic selection in mountain lions could result in nonlinear relationships. For example, with slope they may prefer mid-range values, avoiding flat areas and extremely steep cliffs. Therefore, we also entered all topographic metrics as quadratic terms, resulting in competing models formulated as topographic metric + topographic metric ${ }^{2}+$ $\mathrm{EVH}+$ topographic metric $\mathrm{x} \mathrm{EVH}$.

To contrast topographic variable selection at the population level, to how an individual mountain lion may use topography, we selected a mountain lion whose home range encompassed the San Francisco Peaks and Mount Elden just north of the city of Flagstaff, Arizona. This home range encompasses an area of high elevation (2100-3700 m) with strong seasonality, where snow may be a factor in mountain lion movements during the winter months and solar radiation has a strong effect on snow cover and depth. We hypothesize that a mountain lion's response to aspect may change throughout the year southern aspects are more likely to be used in the winter and, conversely, northerly aspects are more likely to be used during the summer. To account for this we used the ordinal date in an interaction term and included a quadratic term in the models comparing measures of orientation. The mountain lion we selected for this analysis had a GPS fix success rate of $75 \%$, totaling 2,395 fix locations at a 4-hour fix interval, and a total of 499 days of continuous monitoring. We generated an equal number of absence/random background locations using Geospatial Modeling Environment [64], where absences were paired with observations to be within the $99^{\text {th }}$ percentile step-length for that study animal. Like our population level assessment, we entered EVH as an interaction term and quadratic relationships were used for comparing metrics of complexity and form. 


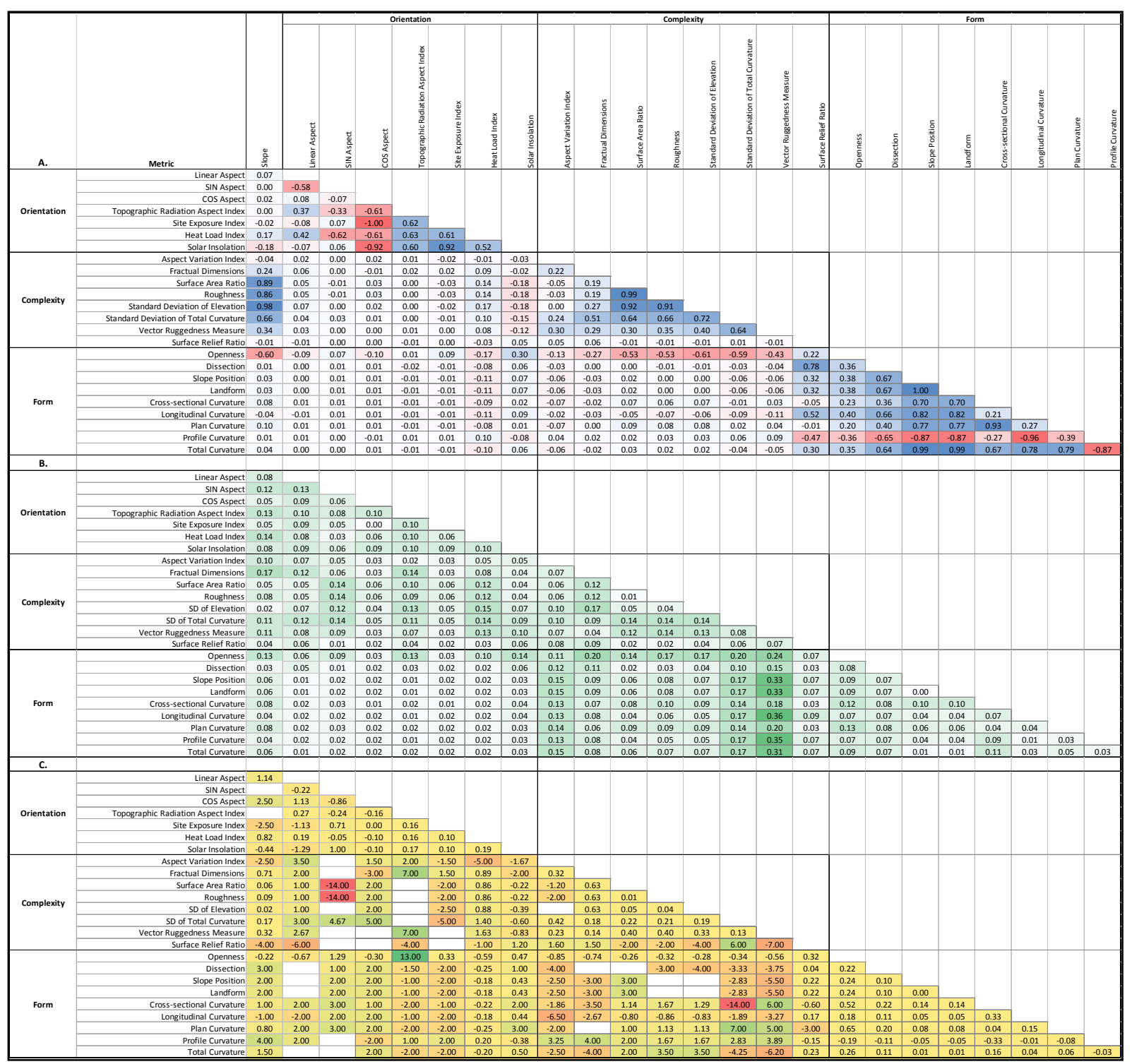

Figure. 4. Heat map of mean Pearson correlation coefficient matrix for metrics calculated at a 30-m resolution across five physiographic extents (A.), the associated standard deviation around the mean (B.), and the coefficient of variation (C.). 
Table 1. Population level resource selection model comparisons

\begin{tabular}{|c|c|c|c|c|c|}
\hline & & \multicolumn{4}{|c|}{ Weighted } \\
\hline & Terrain Measure - 1 km & Deviance & $\Delta_{D e v}$ & Dev R-sq (adj) & Rank \\
\hline \multirow{8}{*}{ Complexity } & Aspect Variation Index & 215526 & 2680 & $5.71 \%$ & 8 \\
\hline & Fractual Dimensions & 213761 & 915 & $6.49 \%$ & 2 \\
\hline & Surface Area Ratio & 215152 & 2306 & $5.88 \%$ & 7 \\
\hline & Roughness & 214891 & 2045 & $5.99 \%$ & 6 \\
\hline & SD of Elevation & 214279 & 1433 & $6.26 \%$ & 3 \\
\hline & SD of Total Curvature & 212846 & 0 & $6.89 \%$ & 1 \\
\hline & \begin{tabular}{|l|} 
Vector Ruggedness Measure \\
\end{tabular} & 215977 & 3131 & $5.52 \%$ & 11 \\
\hline & Surface Relief Ratio & 215952 & 3106 & $5.53 \%$ & 10 \\
\hline \multirow{10}{*}{ Form } & Openness & 214819 & 1973 & $6.02 \%$ & 5 \\
\hline & Dissection & 217667 & 4821 & $4.78 \%$ & 18 \\
\hline & Slope Position & 216505 & 3659 & $5.29 \%$ & 13 \\
\hline & Landform & 216505 & 3659 & $5.29 \%$ & 14 \\
\hline & Cross-sectional Curvature & 216925 & 4079 & $5.10 \%$ & 16 \\
\hline & Longitudinal Curvature & 215814 & 2968 & $5.59 \%$ & 9 \\
\hline & Plan Curvature & 217238 & 4392 & $4.96 \%$ & 17 \\
\hline & Profile Curvature & 216126 & 3280 & $5.45 \%$ & 12 \\
\hline & Total Curvature & 216739 & 3893 & $5.18 \%$ & 15 \\
\hline & Slope & 214530 & 1684 & $6.15 \%$ & 4 \\
\hline \multirow{2}{*}{\multicolumn{2}{|c|}{$\begin{array}{c}\text { SD of Total Curvature + Fractual } \\
\text { Dimensions + Openness }\end{array}$}} & 207299 & - & $9.31 \%$ & - \\
\hline & & & & & \\
\hline & & \multicolumn{4}{|c|}{ Weighted } \\
\hline & Terrain Measure - $\mathbf{3 0} \mathbf{~ m}$ & Deviance & $\Delta_{D e v}$ & Dev R-sq (adj) & Rank \\
\hline \multirow{8}{*}{ Complexity } & Aspect Variation Index & 216602 & 4886 & $5.24 \%$ & 8 \\
\hline & Fractal Dimensions & 214600 & 2884 & $6.12 \%$ & 3 \\
\hline & Surface Area Ratio & 215658 & 3942 & $5.66 \%$ & 6 \\
\hline & Roughness & 215711 & 3995 & $5.63 \%$ & 7 \\
\hline & SD of Elevation & 215091 & 3375 & $5.90 \%$ & 4 \\
\hline & SD of Total Curvature & 215555 & 3839 & $5.70 \%$ & 5 \\
\hline & \begin{tabular}{|l|} 
Vector Ruggedness Measure \\
\end{tabular} & 217437 & 5721 & $4.88 \%$ & 14 \\
\hline & Surface Relief Ratio & 217648 & 5932 & $4.79 \%$ & 18 \\
\hline \multirow{10}{*}{ Form } & Openness & 211716 & 0 & $7.38 \%$ & 1 \\
\hline & Dissection & 217456 & 5740 & $4.87 \%$ & 15 \\
\hline & Slope Position & 217277 & 5561 & $4.95 \%$ & 11 \\
\hline & Landform & 217277 & 5561 & $4.95 \%$ & 12 \\
\hline & Cross-sectional Curvature & 217592 & 5876 & $4.81 \%$ & 17 \\
\hline & Longitudinal Curvature & 217206 & 5490 & $4.98 \%$ & 10 \\
\hline & Plan Curvature & 217559 & 5843 & $4.82 \%$ & 16 \\
\hline & Profile Curvature & 217200 & 5484 & $4.98 \%$ & 9 \\
\hline & Total Curvature & 217279 & 5563 & $4.95 \%$ & 13 \\
\hline & Slope & 213734 & 2018 & $6.50 \%$ & 2 \\
\hline \multirow{2}{*}{\multicolumn{2}{|c|}{$\begin{array}{c}\text { Openness }+ \text { SD of Elevation + Fractual } \\
\text { Dimensions }\end{array}$}} & 207854 & - & $9.07 \%$ & - \\
\hline & & & & & \\
\hline & & \multicolumn{4}{|c|}{ Unweighted } \\
\hline & Terrain Measure - $\mathbf{3 0} \mathbf{~ m}$ & Deviance & $\Delta_{D e v}$ & Dev R-sq (adj) & Rank \\
\hline \multirow{8}{*}{ Complexity } & Aspect Variation Index & 192148 & 1906 & $4.81 \%$ & 6 \\
\hline & Fractal Dimensions & 190242 & 0 & $5.75 \%$ & 1 \\
\hline & Surface Area Ratio & 193161 & 2919 & $4.31 \%$ & 8 \\
\hline & Roughness & 193271 & 3029 & $4.25 \%$ & 10 \\
\hline & SD of Elevation & 191804 & 1562 & $4.98 \%$ & 5 \\
\hline & SD of Total Curvature & 191743 & 1501 & $5.01 \%$ & 4 \\
\hline & Vector Ruggedness Measure & 192676 & 2434 & $4.55 \%$ & 7 \\
\hline & Surface Relief Ratio & 193745 & 3503 & $4.02 \%$ & 16 \\
\hline \multirow{10}{*}{ Form } & Openness & 191187 & 945 & $5.28 \%$ & 3 \\
\hline & Dissection & 193224 & 2982 & $4.27 \%$ & 9 \\
\hline & Slope Position & 193720 & 3478 & $4.03 \%$ & 14 \\
\hline & Landform & 193720 & 3478 & $4.03 \%$ & 15 \\
\hline & Cross-sectional Curvature & 193589 & 3347 & $4.09 \%$ & 11 \\
\hline & Longitudinal Curvature & 193801 & 3559 & $3.99 \%$ & 18 \\
\hline & Plan Curvature & 193648 & 3406 & $4.06 \%$ & 12 \\
\hline & Profile Curvature & 193777 & 3535 & $4.00 \%$ & 17 \\
\hline & Total Curvature & 193716 & 3474 & $4.03 \%$ & 13 \\
\hline & Slope & 190985 & 743 & $5.38 \%$ & 2 \\
\hline \multicolumn{2}{|c|}{ Fractal Dimensions + Slope + Aspect } & 187434 & - & $7.15 \%$ & - \\
\hline
\end{tabular}




\section{Results and Discussion}

Using competing models to select topographic metrics best explaining where mountain lions occur on the landscape, we found sensitivities to the scale, method of specification, and if detection-bias correction factors were used (Tables 1 and 2). For the population level model (Table 1), including all observations corrected for detection bias, and $1-\mathrm{km}$ resolution metrics, our measure of topographic complexity, standard deviation of total curvature, was ranked number one. Next were fractal dimensions, standard deviation of elevation, and slope. Using the top three ranked variables that are not correlated (defined as $<0.70$ ) resulted in a model including standard deviation of total curvature, fractal dimensions, and openness. Changing the resolution of calculation to a $30-\mathrm{m}$ resolution resulted in openness being the top ranked topographic metric, with slope and fractal dimensions being ranked second and third respectively. Taking the top three ranked uncorrelated metrics resulted in a model using openness, standard deviation of elevation, and fractal dimensions. Staying at the $30-\mathrm{m}$ resolution but not weighting the observations to correct for detection bias, resulted in fractal dimensions being the top-ranked metric. This was followed by slope and openness. A model using the top three uncorrelated metrics resulted in including fractal dimensions, slope and the aspect variation index.

When we subsetted the dataset to observations of a single cougar whose home range encompassed the San Francisco Peaks and Mount Elden (Figure 2E) the top ranked variables changed once again (Table 2). For both the weighted and unweighted model comparisons, slope, standard deviation of elevation, and surface area ratio were the top-three ranked metrics. Of the orientation measures that were included in these model comparisons, the site exposure index was the top ranked orientation metric. The top four uncorrelated metrics were slope, standard deviation of total curvature, openness, and site exposure index.

We found no one measure had pronounced predictive power over the others and the most deviance was explained by multivariate models incorporating several characteristics of the terrain in our study area. How the models were approached in terms of scale and with the use of correction factors for the effect terrain has on GPS performance, influenced variable selection. How the data were analyzed in terms of a population-wide versus background analysis or that of an individual (accounting for movement capacity) also influenced the best combination of metrics.

Because the top ranked variables in our example with mountain lions were often correlated, we chose the next top ranked variable with $<0.70$ correlation coefficient to include in the model. This was a driver for the ensemble of metrics to change from comparison to comparison. There was some consistency between the upper-ranked metrics for mountain lions: standard deviation of total curvature, fractal dimensions, openness, slope, and standard deviation of elevation were the most important metrics for measures of complexity and form. The comparison including measures of orientation resulted in the site exposure index (ranked 7th out of 24) being the best metric of orientation. Site exposure index was followed by solar insolation; these two measures of orientation were also highly positively correlated in all of the comparisons.

Table 2. Individual level resource selection model comparison

\begin{tabular}{|c|c|c|c|c|c|c|c|c|c|}
\hline & \multirow[b]{2}{*}{ Terrain Measure } & \multicolumn{4}{|c|}{ Weighted } & \multicolumn{4}{|c|}{ Unweight ed } \\
\hline & & Deviance & $\Delta_{\text {Dev }}$ & Dev R-sq (adj) & Rank & Deviance & $\Delta_{D e v}$ & Dev R-sq (adj) & Rank \\
\hline \multirow{7}{*}{ Orientation $(k=6)$} & Linear Aspect & 14920 & 1431 & $0.20 \%$ & 24 & 6625 & 673 & $0.14 \%$ & 25 \\
\hline & SIN Aspect & 14529 & 1040 & $282 \%$ & 9 & 6447 & 495 & $2.83 \%$ & 9 \\
\hline & COS Aspect & 14544 & 1055 & $272 \%$ & 10 & 6447 & 496 & $2.82 \%$ & 10 \\
\hline & Topographic Radiation Aspect Index & 14864 & 1376 & $0.57 \%$ & 19 & 6603 & 652 & $0.47 \%$ & 19 \\
\hline & Site Exposure Index & 14438 & 949 & $3.43 \%$ & 7 & 6403 & 451 & $3.49 \%$ & 7 \\
\hline & Heat Load Index & 14912 & 1423 & $0.26 \%$ & 22 & 6623 & 672 & $0.17 \%$ & 23 \\
\hline & Solar Insolation & 14485 & 996 & $3.11 \%$ & 8 & 6421 & 470 & $3.21 \%$ & 8 \\
\hline \multirow{8}{*}{ Complexity ( $k=4)$} & Aspect Variation Index & 14858 & 1369 & $0.63 \%$ & 18 & 6595 & 644 & $0.62 \%$ & 18 \\
\hline & Fractal Dimensions & 14773 & 1284 & $120 \%$ & 14 & 6557 & 606 & $1.19 \%$ & 12 \\
\hline & Surface Area Ratio & 13941 & 453 & $6.76 \%$ & 3 & 6156 & 205 & $7.24 \%$ & 3 \\
\hline & Roughness & 13957 & 469 & $6.65 \%$ & 4 & 6164 & 213 & $7.11 \%$ & 4 \\
\hline & SD of Elevation & 13503 & 14 & $9.69 \%$ & 2 & 5957 & 5 & $10.24 \%$ & 2 \\
\hline & SD of Total Curvature & 14204 & 716 & $5.00 \%$ & 5 & 6287 & 336 & $5.25 \%$ & 5 \\
\hline & Vector Ruggedness Measure & 14690 & 1202 & $175 \%$ & 11 & 6512 & 561 & $1.88 \%$ & 11 \\
\hline & Surface Relief Ratio & 14910 & 1421 & $0.28 \%$ & 21 & 6619 & 668 & $0.26 \%$ & 21 \\
\hline \multirow{10}{*}{ Form $(k=4)$} & Openness & 14279 & 790 & $4.50 \%$ & 6 & 6307 & 356 & $4.96 \%$ & 6 \\
\hline & Dissection & 14916 & 1427 & $0.24 \%$ & 23 & 6622 & 671 & $0.22 \%$ & 22 \\
\hline & Slope Position & 14804 & 1315 & $0.99 \%$ & 15 & 6578 & 626 & $0.89 \%$ & 15 \\
\hline & Landform & 14804 & 1315 & $0.99 \%$ & 16 & 6578 & 626 & $0.89 \%$ & 16 \\
\hline & Cross-sectional Curvature & 14763 & 1274 & $127 \%$ & 12 & 6561 & 610 & $1.13 \%$ & 13 \\
\hline & Longitudinal Curvature & 14920 & 1432 & $0.21 \%$ & 25 & 6623 & 672 & $0.20 \%$ & 24 \\
\hline & Plan Curvature & 14769 & 1280 & $122 \%$ & 13 & 6565 & 613 & $1.08 \%$ & 14 \\
\hline & Profile Curvature & 14893 & 1405 & $0.39 \%$ & 20 & 6612 & 661 & $0.36 \%$ & 20 \\
\hline & Total Curvature & 14811 & 1322 & $0.95 \%$ & 17 & 6581 & 630 & $0.83 \%$ & 17 \\
\hline & Slope & 13489 & 0 & $9.78 \%$ & 1 & 5951 & 0 & $10.32 \%$ & 1 \\
\hline \multicolumn{2}{|c|}{$\begin{array}{r}\text { Slope }+S D \text { of Total Curvature + Openness + Site Exposure Index } \\
(k=14)\end{array}$} & 13340 & & $10.72 \%$ & & & & & \\
\hline
\end{tabular}




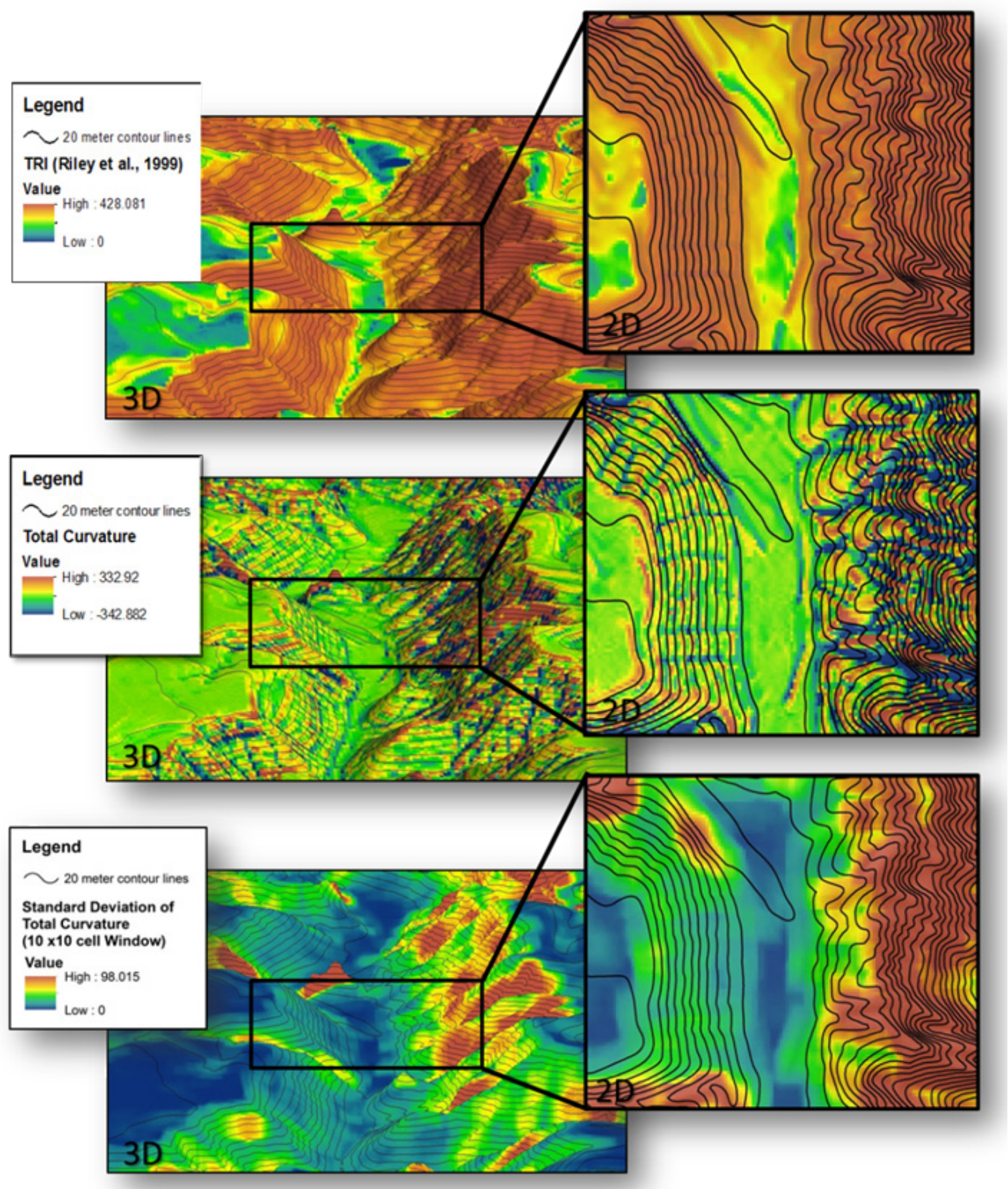

Figure 5. Raster maps of a valley shown in $3 \mathrm{D}$ from a view point (left panels) and $2 \mathrm{D}$ bird's eye view (right panels), where the left side of the valley is steep and relatively flat faced, while the right side of the valley is steep but undulating and complex faced. Many measures meant to capture complexity, such as TRI, do not distinguish between steepness and ruggedness (Top Panels). Curvature, a metric of form, captures ridges and draws (Middle Panels). Calculating the variability in form (standard deviation of curvature) for an analysis window differentiates between flat faced slopes and those with undulating or broken features (Bottom Panel). 
Standard deviation of total curvature was developed during our review to better capture topographic complexity. The typical complexity measures we found do not distinguish between steep slopes and broken or "rugged" terrain [2]. Using focal statistics of the neighborhood around a cell to quantify the variability in form (Figure 5) appears to be a way to identify complex, uneven-faced slopes from flat-faced slopes. At a coarse scale, this appears to best explain the occurrence of mountain lions as a population across our study area. Whether or not the size of area, i.e. the analysis window size, with rugged configuration plays a role in mountain lion resource selection needs further exploration. Characterization of mountain lion use of topography has been addressed by several researchers; Riley [45-47] developed the terrain ruggedness index (TRI) for assessing resource selection of mountain lions in Montana; Dickson et al. [59], Dickson and Beier [15], and Dickson et al. [60] applied the topographic position index (TPI); and Burdett et al. [61] used vector ruggedness measure (VRM) for describing mountain lion movement in southern California. None of these measures ranked high in our model comparisons for northern Arizona, suggesting characterizing topography and how these top predators orient to terrain features on the landscape can be improved upon.

\section{Conclusions}

Digital elevation models can provide critical information on how organisms relate to terrestrial landscapes. However, the multitude of metrics available and the unknown sensitivities to specification can be overwhelming in applied landscape scale studies. In general, the coarser the spatial grain, the more similar metrics can become, but the degree that terrain measures were affected varied for several metrics. Similarly, changes in extent resulted in some metrics being more sensitive than others in how correlated they were with other metrics, but highly correlated metrics appear to be rather robust to change in physiography. We caution that some measures of topographic complexity are not able to distinguish steepness of slope from uneven or rugged terrain. For mountain lions, we found rarely employed metrics to be the best ranked in model comparisons - first, a metric calculating variation in topographic form, next, another complexity metric, fractal dimensions, and, lastly, one that relies on the view-shed concept of openness. Many wildlife resource selection studies have focused on terrain measures capturing particular features of landscapes such as steepness or a particular landform, but analysis of mountain lions showed configuration of terrain patches and how topography influences visibility to be the most important. How view-sheds are used by animals needs further exploration but could provide meaningful insight into predator-prey dynamics. Metric ranking was influenced by detection correction measures and is another consideration in relating occurrence with terrain. No single metric outperformed a multivariate approach, suggesting landscape ecologists may not want to rely on a single metric of topography. Quantifying how organisms orient to topography is not resolved and many aspects of how terrain is characterized need further exploration in terms of analysis window affects. The use of focal statistics of continuous measures is an area of landscape quantification that shows promise for improving our understanding of how animals respond to terrain.

\section{Acknowledgements}

This study was funded by the NASA Biodiversity and Ecological Forecasting Program (Climate and Biological Response, grant no. NNH10ZFA001N). Financial support for the collection of cougar datasets was provided by the USGS Park-Oriented Biological Support program, the USGS Colorado Plateau Research Station, the NPS Cooperative Conservation Initiative, the Summerlee Foundation, the Wilburforce Foundation, the USGS Southwest Biological Science Center, the USGS Fire Research Program, the Johnson Family Foundation, and Grand Canyon National Park. Material and other in-kind support has been provided by USDA Wildlife Services, The Grand Canyon Trust, Northern Arizona University, Arizona Game and Fish Department, and the NPS Flagstaff Area National Monuments. We thank Kathy Longshore and Dan Thompson for helpful thoughts related to topography and wildlife. We thank Jan Hart, Brian Jansen, Erik York, Sam Dieringer, and JR Murdock for capture, handling, and tagging of mountain lions. We thank Jeffrey Lovich, Amy Whipple and an anonymous reviewer for helpful reviews and comments. The use of trade, product, or firm names in this publication is for descriptive purposes only and does not imply endorsement by the U.S. Government.

\section{REFERENCES}

[1] Pike R, Evans I, Hengl T: Geomorphometry: a brief guide. Developments in Soil Science 2009, 33:3-30.

[2] Sappington JM, Longshore KM, Thompson DB: Quantifying landscape ruggedness for animal habitat analysis: a case study using bighorn sheep in the Mojave Desert. Journal of Wildlife Management 2007, 71:1419-1426.

[3] Tesfa TK, Tarboton DG, Watson DW, Schreuders KA, Baker ME, Wallace RM: Extraction of hydrological proximity measures from DEMs using parallel processing. Environmental Modelling \& Software 2011, 26:1696-1709.

[4] Janczewski DN, Modi WS, Stephens JC, O'Brien SJ: 
Molecular evolution of mitochondrial 12S RNA and cytochrome $b$ sequences in the pantherine lineage of Felidae. Molecular Biology and Evolution 1995, 12:690-707.

[5] Meloro C, Elton S, Louys J, and Bishop LC, Ditchfield P: Cats in the forest: predicting habitat adaptations from humerus morphometry in extant and fossil Felidae (Carnivora). Paleobiology 2013, 39:323-344.

[6] Bryce CM, Wilmers CC, Williams TM: Energetics and evasion dynamics of large predators and prey: pumas vs. hounds. PeerJ 2017, 5:e3701.

[7] Stage AR: Notes: An expression for the effect of aspect, slope, and habitat type on tree growth. Forest Science 1976, $22: 457-460$

[8] Davies RG, Orme CDL, Storch D, Olson VA, Thomas GH, Ross SG, Ding T-S, Rasmussen PC, Bennett PM, Owens IP: Topography, energy and the global distribution of bird species richness. Proceedings of the Royal Society of London B: Biological Sciences 2007, 274:1189-1197.

[9] Yard MD, Bennett GE, Mietz SN, Coggins LG, Stevens LE, Hueftle S, Blinn DW: Influence of topographic complexity on solar insolation estimates for the Colorado River, Grand Canyon, AZ. Ecological Modelling 2005, 183:157-172.

[10] Rich P, Dubayah R, Hetrick W, Saving S: Using viewshed models to calculate intercepted solar radiation: applications in ecology. American Society for Photogrammetry and Remote Sensing Technical Papers. In American Society of Photogrammetry and Remote Sensing. 1994: 524-529.

[11] Rich PM, Fu P: Topoclimatic habitat models. In Proceedings of the fourth international conference on integrating GIS and environmental modeling. 2000: 2-8.

[12] MacMillan R, Shary $\mathrm{P}$, Hengl $\mathrm{T}$, and Reuter $\mathrm{H}$ : Geomorphometry: concepts, software, applications. Elsevier Science. Chap. Landforms and Landforms elements in geomorphometry; 2008.

[13] McNab WH: Terrain shape index: quantifying effect of minor landforms on tree height. Forest Science 1989, 35:91-104.

[14] McNab WH: A topographic index to quantify the effect of mesoscale landform on site productivity. Canadian Journal of Forest Research 1993, 23:1100-1107.

[15] Dickson BG, Beier P: Quantifying the influence of topographic position on cougar (Puma concolor) movement in southern California, USA. Journal of Zoology 2007, 271:270-277.

[16] Wiens: JA. Spatial scaling in ecology. Functional Ecology 1989, 3:385-397.

[17] $\mathrm{Wu} \mathrm{J}$ : Effects of changing scale on landscape pattern analysis: scaling relations. Landscape Ecology 2004, 19:125-138.

[18] Wu J, Shen W, Sun W, Tueller PT: Empirical patterns of the effects of changing scale on landscape metrics. Landscape Ecology 2002, 17:761-782.

[19] Urban DL: Modeling ecological processes across scales. Ecology 2005, 86:1996-2006.

[20] Frazier AE: Surface metrics: scaling relationships and downscaling behavior. Landscape Ecology 2016, 31:351-363.

[21] Frazier AE, Kedron P: Landscape Metrics: Past Progress and Future Directions. Current Landscape Ecology Reports 2017, 2:63-72.

[22] Wood J: Geomorphometry in LandSerf. Developments in Soil Science 2009, 33:333-349.

[23] Bouchet PJ, Meeuwig JJ, Kent S, Chandra P, Letessier TB, Jenner CK: Topographic determinants of mobile vertebrate predator hotspots: current knowledge and future directions. Biological Reviews 2015, 90:699-728.

[24] Kerr JT, Packer L: Habitat heterogeneity as a determinant of mammal species richness in high-energy regions. Nature 1997, 385:252.

[25] Jetz W, Rahbek C: Geographic range size and determinants of avian species richness. Science 2002, 297:1548-1551.

[26] Worm B, Lotze HK, Myers RA: Predator diversity hotspots in the blue ocean. Proceedings of the National Academy of Sciences 2003, 100:9884-9888.

[27] Morato T, Hoyle SD, Allain V, Nicol SJ: Seamounts are hotspots of pelagic biodiversity in the open ocean. Proceedings of the National Academy of Sciences 2010, 107:9707-9711.

[28] Alexander SM: Snow tracking and GIS: using multiple species environment models to determine optimal wildlife crossing sites and evaluate highway mitigation plans on the Trans-Canada Highway. The Canadian Geographer/Le Géographe Canadien 2008, 52:169-187.

[29] U.S. Geological Survey: National Elevation Dataset (NED)--Raster digital data. (U.S. Geological Survey ed., 2nd edition edition. Sioux Falls: The National Map; 2009.

[30] Pittman SJ, Costa BM, Battista TA: Using lidar bathymetry and boosted regression trees to predict the diversity and abundance of fish and corals. Journal of Coastal Research 2009:27-38.

[31] Larkin D, Vivian-Smith G, Zedler JB: Topographic heterogeneity theory and ecological restoration. Foundations of restoration ecology 2006:142-164.

[32] Ott RL, Longnecker MT: An introduction to statistical methods and data analysis. Nelson Education; 2015.

[33] Esri: ArcGIS Desktop Release 10.2. Redlands: Environmental Systems Resource Institute, http://www.esri.com/; 2013.

[34] Evans J, Oakleaf J, Cushman S, Theobald D: An ArcGIS toolbox for surface gradient and geomorphometric modeling, version 2.0-0. Laramie, WY, http://evansmurphywix.com/evansspatial; 2014.

[35] Ironside KE, Mattson DJ, Choate D, Stoner D, Arundel TR, Theimer TC, Holton B, Jansen B, Sexton J, Longshore KM, et al: Variable Terrestrial GPS Telemetry Detection Rates: Parts 1 - 7. (U.S. Geological Survey ed. Flagstaff: U.S Geological Survey, 10.5066/F7PG1PT2; 2015.

[36] Roberts DW, Cooper SV: Concepts and techniques of vegetation mapping. General Technical Report INT-US Department of Agriculture, Forest Service, Intermountain 
Research Station (USA) 1989.

[37] Balice RG, Miller JD, Oswald BP, Edminster C, Yool SR: Forest Surveys and Wildlife Assessment in the Los Alamos Region: 1998-1999. Los Alamos National Laboratory; 2000.

[38] McCune B, Keon D, Marrs R: Equations for potential annual direct incident radiation and heat load. Journal of vegetation science 2002, 13:603-606.

[39] Fu P, Rich P: The solar analyst 1.0 user manual. Helios Environmental Modeling Institute 2000, 1616.

[40] Fu P, Rich PM: A geometric solar radiation model with applications in agriculture and forestry. Computers and electronics in agriculture 2002, 37:25-35.

[41] Nielsen SE, Herrero S, Boyce MS, Mace RD, Benn B, Gibeau ML, and Jevons S: Modelling the spatial distribution of human-caused grizzly bear mortalities in the Central Rockies ecosystem of Canada. Biological Conservation 2004, 120:101-113.

[42] Mark DM, Aronson PB: Scale-dependent fractal dimensions of topographic surfaces: an empirical investigation, with applications in geomorphology and computer mapping. Mathematical Geology 1984, 16:671-683.

[43] Berry J: Beyond mapping use surface area for realistic calculations. Geo World 2002, 15:20-21.

[44] Jenness JS: Calculating landscape surface area from digital elevation models. Wildlife Society Bulletin 2004, 32:829-839.

[45] Riley SJ: Integration of environmental, biological, and human dimensions for management of mountain lions (Puma concolor) in Montana. Cornell University, 1998.

[46] Riley SJ: Index That Quantifies Topographic Heterogeneity. Intermountain Journal of sciences 1999, 5:23-27.

[47] Riley SJ, Malecki RA: A landscape analysis of cougar distribution and abundance in Montana, USA. Environmental Management 2001, 28:317-323.

[48] Pike RJ, Wilson SE: Elevation-relief ratio, hypsometric integral and geomorphic area-altitude analysis. Geological Society of America Bulletin 1971, 82:1079-1084.

[49] Yokoyama R, Shirasawa M, Pike RJ: Visualizing topography by openness: a new application of image processing to digital elevation models. Photogrammetric engineering and remote sensing 2002, 68:257-266.

[50] Evans I: General geomorphometry, derivatives of altitude, and descriptive statistics. In Spatial Analysis in Geomorphology. Edited by Chorley RJ. New York: Harper \& Row; 1972: 17-90

[51] De Reu J, Bourgeois J, Bats M, Zwertvaegher A, Gelorini V, De Smedt P, Chu W, Antrop M, De Maeyer P, Finke P: Application of the topographic position index to heterogeneous landscapes. Geomorphology 2013 , 186:39-49.

[52] Guisan A, Weiss SB, Weiss AD: GLM versus CCA spatial modeling of plant species distribution. Plant Ecology 1999, 143:107-122.

[53] Bolstad PV, Lillesand T: Improved classification of forest vegetation in northern Wisconsin through a rule-based combination of soils, terrain, and Landsat Thematic Mapper data. Forest Science 1992, 38:5-20.

[54] Bodie WL, Garton EO, Taylor ER, McCoy M: A sightability model for bighorn sheep in canyon habitats. The Journal of Wildlife Management 1995:832-840.

[55] Frair JL, Fieberg J, Hebblewhite M, Cagnacci F, DeCesare NJ, Pedrotti L: Resolving issues of imprecise and habitat-biased locations in ecological analyses using GPS telemetry data. Philosophical Transactions of the Royal Society of London B: Biological Sciences 2010, $365: 2187-2200$.

[56] Ironside KE, Mattson DJ, Choate D, Stoner D, Arundel T, Hansen J, Theimer T, Holton B, Jansen B, Sexton JO: Variable terrestrial GPS telemetry detection rates: Addressing the probability of successful acquisitions. Wildlife Society Bulletin 2017.

[57] Mattson DJ: Mountain Lions of the Flagstaff Uplands: 2003-2006 Progress Report. 2007.

[58] Getz WM, Fortmann-Roe S, Cross PC, Lyons AJ, Ryan SJ, Wilmers CC: LoCoH: nonparameteric kernel methods for constructing home ranges and utilization distributions. PloS one 2007, 2:e207.

[59] Dickson BG, Jenness JS, Beier P: Influence of vegetation, topography, and roads on cougar movement in southern California. Journal of Wildlife Management 2005, 69:264-276.

[60] Dickson BG, Roemer GW, McRae BH, Rundall JM: Models of regional habitat quality and connectivity for pumas (Puma concolor) in the southwestern United States. PloS one 2013, 8:e81898.

[61] Burdett CL, Crooks KR, Theobald DM, Wilson KR, Boydston EE, Lyren LM, Fisher RN, Vickers TW, Morrison SA, Boyce WM: Interfacing models of wildlife habitat and human development to predict the future distribution of puma habitat. Ecosphere 2010, 1:1-21.

[62] 62. Manly B, McDonald L, Thomas D, McDonald TL and Erickson WP: Resource selection by animals: statistical design and analysis for field studies. Springer Science \& Business Media; 2007.

[63] LANDFIRE: LANDFIRE 1.1.0--Existing vegetation height and type layers. (LANDFIRE ed., 1.1.0 edition: U.S Department of Agriculture and U.S. Department of the Interior; 2011.

[64] Beyer HL: Geospatial modelling environment. http://www spatialecology com/gme 2010. 